\title{
EVS25
}

Shenzhen, China, Nov 5-9, 2010

\section{On-line Parameter Estimation Method for IPMSM Based on Decoupling Control}

\author{
Aimeng Wang,Xingwang Jia,Wenjuan Shi \\ School of Electrical and Electronic Engineering, North China Electric Power University, \\ 619 North of Yonghua Street, Baoding, Hebei, China \\ E-mail: aimeng_068@163.com
}

\begin{abstract}
This paper proposed on-line parameter estimation method to compensate the magnetic cross-saturation effect on the interior permanent magnet synchronous motor (IPMSM) control system for electric vehicle. The decoupling control model for IPMSM with magnetic saturation compensation based on SVPWM (Space Vector PWM) method is established. Though comparing the simulation results between model with saturation compensation of parameter estimation and ones without saturation compensation, it is verified that the control performance with saturation compensation is more stable and more accurate than that of without compensation over speed operating region especially at higher speed. The on-line parameter estimation method based on decoupling control improves the system following-up performance, robustness and the control accuracy effectively.
\end{abstract}

Keywords: Decoupling control, Compensation of magnetic saturation, SVPWM, On-line parameter estimation

\section{Introduction}

IPMSM has become popular choices for high-performance traction applications used in production hybrid vehicles including the Toyota Prius, and Ford Escape. The emergence has been driven by a combination of factors including the cost reduction of magnet material and the attractive performance features of IPMSM that include high power density, high efficiency, and an ability to achieve wide speed ranges of constant-power operation[1-3].

IPMSM is nonlinear and strongly cross-coupling system with many variable parameters. Since the effective air gap in the IPMSM is small and therefore, the effects of magnetic saturation and cross-saturation are 
dominant, which influence its control performances [4]. Mostly previous work reported in the literature has focused on cross saturation model and saturation impacts on IPMSM drives [5-8]. In this paper, the purpose is to present an improved current control method for IPMSM considering for magnetic saturation and cross-coupling based on decoupling control method by using SVPWM technology. Since the inductance is a function of $\mathrm{d}$ - and q-axes current that vary with operating conditions due to magnetic saturation, the compensated value of inductance is used in the control algorithm. Several models of IPMSM drives are set up by using different parameters including linear and nonlinear magnetic cross-saturation inductance parameters of the machine in flux-weakening control. Through the comparison of different models verify the excellent performance of the control system with decoupling control and compensation of magnetic saturation.

\section{Parameter Characteristic and}

\section{Effect of Magnetic Saturation}

\subsection{The IPM Machine Parameter Characteristic}

Asymmetric rotor structure of IPMSM makes the d- and q-axes inductances different and exist serious cross-saturation, which will affect the accuracy of output torque and stability of the control system.

For IPMSM, due to the permanent magnet axial position in the d-axis and the larger effective air-gap length on the d-axis, the variation of magnetizing reactance depending on $I_{d}$ current is minimal and therefore the $L_{d}$ is assumed constant value. However, the effective air-gap length on the $\mathrm{q}$-axis is small and the magnetic saturation is dominant. The q-axis inductance varies depending on the q-axis current and as a result, the control performance is affected by magnetic saturation. The q- and d-axes inductances changing with qand d-axes currents in IPM motor are shown in figure.1. The q- and d-axes inductance values are respectively $0.47 \mathrm{mH}$ and $0.2 \mathrm{mH}$ in rated operation.
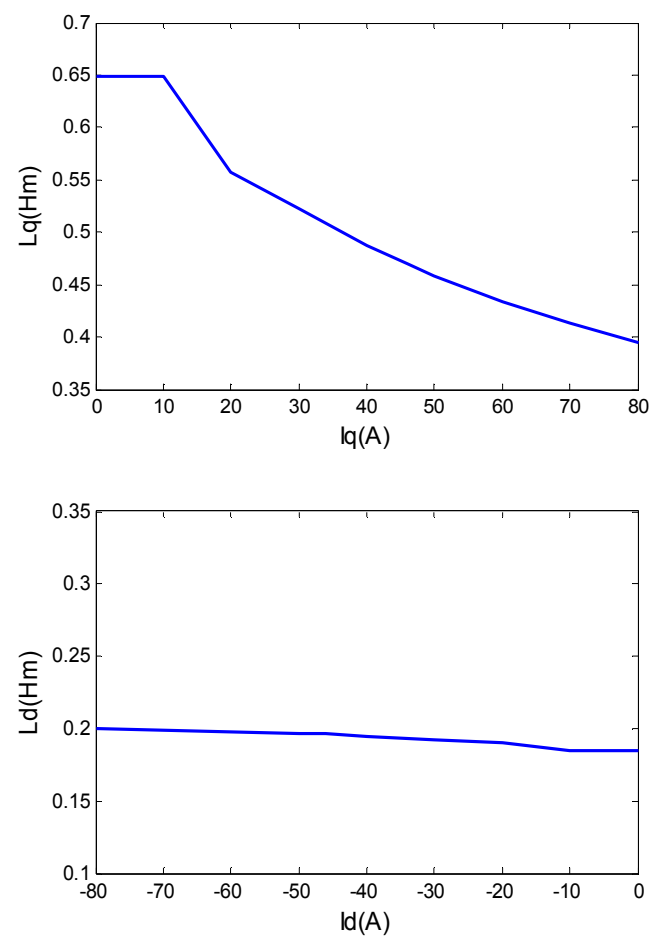

Figure 1: Variation of q- and d-axes inductance versus q- and d-axes current

\subsection{Effect of Magnetic Saturation}

In IPM motor, the main effect of magnetic saturation is that the q-axis inductance $L_{q}$ varies with the q-axis current and the d-axis inductance $L_{d}$ varies with the d-axis current, and, as a result, the control performance is affected. Magnetic saturation produces an interaction or cross-coupling between the dand q-axes. The cross-coupling is presented mainly as the effected of a q-axis current on the back-emf or magnet flux, the back-emf reducing slightly with an increase of q-axis current due to the magnetic saturation on the d-axis. Therefore, the effects of cross-coupling 
exist mainly in the low speed range. The torque and the terminal voltage reduce when the control system operate with maximum torque per amp control, as shown in figure.2. In flux-weakening range, the demagnetizing current $I_{d}$ is increase while $I_{q}$ must be reduced, as a result $L_{q}$ increase as shown in figure 1 . If the $L_{q}$ is assumed to be a constant parameter, i.e the magnetic saturation is ignored, so the control performance become worse and the control system may be unstable. To improve the control system performance, the effect of saturation is compensated using on-line parameter estimation method.

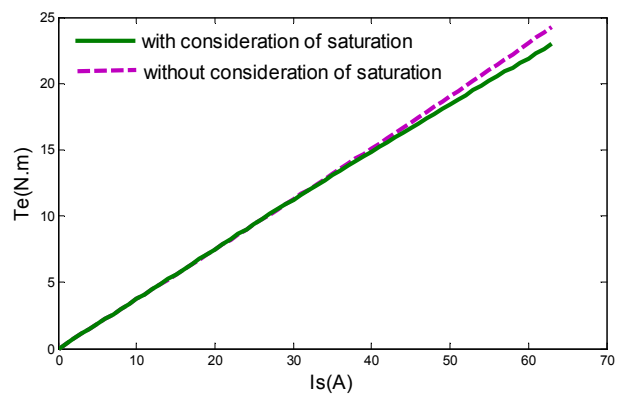

(a)

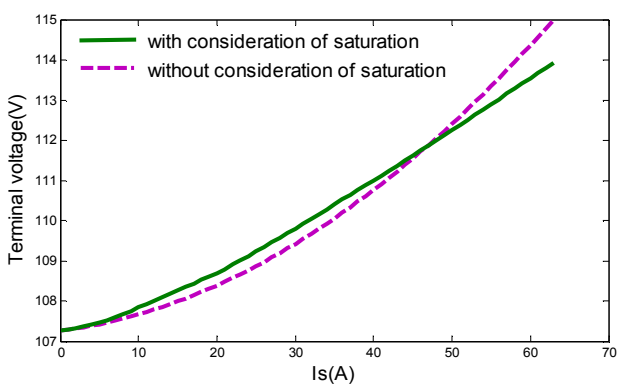

(b)

Figure 2: Comparison of torque and terminal voltage vs .Is current with saturation and without ones at the condition of MTPA region.(a) Torque ; (b) Terminal voltage

\section{Parameter Estimation Method}

\subsection{The On-line Estimation Method of Inductance}

By neglecting the derivative terms of mathematical model of IPMSM which are zero at steady state, we can obtain suitable model equations for efficient and compact parameter estimation, the $\mathrm{d}$ and q-axes inductance estimation model become:

$$
\left\{\begin{array}{l}
L_{d}=\left(U_{q}-R_{s} i_{q}-\omega_{r} \psi_{f}\right) / \omega_{e} i_{d} \\
L_{q}=\left(R_{s} i_{d}-U_{d}\right) / \omega_{e} i_{q}
\end{array}\right.
$$

The estimation parameter from one model is independent of the dynamics of the other model [9]. The parameter estimation model including differentiation terms in mathematical model of IPMSM makes control system complicated and unstable. The inductance parameter motivated by several concerns is variable greatly range, which affects the system stability and accuracy and can not follow precisely inductance parameter variation in motor. So the estimation parameter is compensated by closed loop observer with integrator and the compensation value is $\Delta L_{q}$. The figure. 3 shows the on-line parameter estimation model based on (1). The permanent magnet flux $\Psi_{f}$ and resistance $R_{s}$ are assumed constant value. The $L_{e q}$ is rated value, which improves rapidity of parameter estimation especially in startup transients. The figure. 4 shows the q-axis inductance from on-line parameter estimation model. The output torque and q-axis current have a linear relationship, that is the output torque varies with the q-axis current which makes q-axis inductance nonlinear, so the inductance in control system varies with torque and follows the real one in the machine.

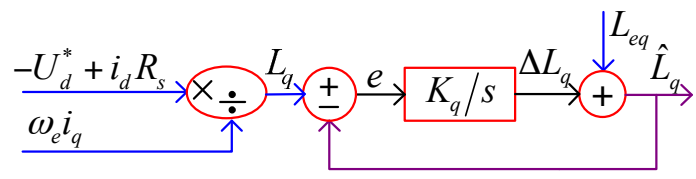

Figure 3: On-line parameter estimation model of q-axis inductance 


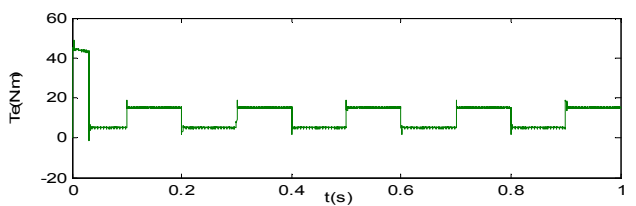

(a)

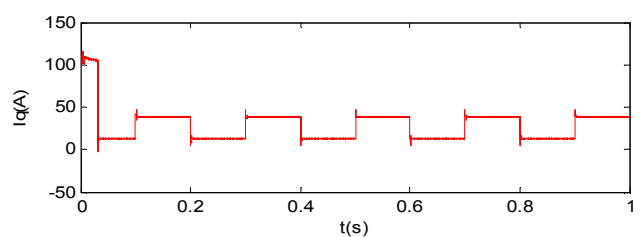

(b)

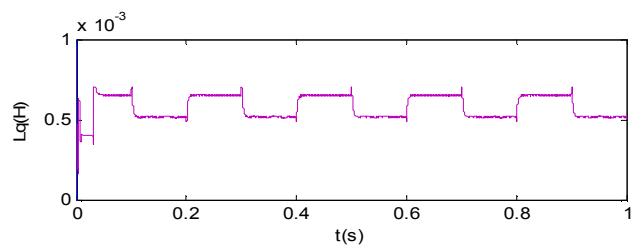

(c)

Figure 4: The q-axis inductance from on-line parameter estimation model (a) Torque; (b) Q-axis current; (c) Q-axis inductance

\subsection{The Decoupling Algorithm}

In the IPMSM vector control system, $I_{d}, I_{q}$ and $U_{d}$, $U_{q}$ exist cross-coupling which is ignored to simplify the control strategy. Especially, in the high-performance control system, this simplification will affect the integration of control performance. The d-and q-axes currents cannot be controlled independently by $U_{d}$ and $U_{q}$, due to cross-coupling effects between $\mathrm{d}$ - and q-axes back-emf. In low-speed region, the influence of cross-coupling is small to the control system. However, the effect increases as the speed increases, especially in high-speed flux-weakening region, the current responses is affected by cross-coupling effect. The terminal voltage exceeds the limited value in this region, the same time, the current controller is saturated and the actual current cannot follow the commanded current. So the feedforward decoupling method is used to compensate the terminal voltage. The decoupling block is added to the speed control system. It eliminates interactions between $\mathrm{d}$ - and q-axes current controls. The decoupling block is shown in figure 5.

Decoupling model is established through theoretical analysis.

$\left\{\begin{array}{l}u_{d e c}=u_{d}^{*}-\omega_{e} \hat{L}_{q} i_{q} \\ u_{q e c}=u_{q}^{*}+\omega_{e}\left(\psi_{f}+L_{d} i_{d}\right)\end{array}\right.$

Where $i_{d}, i_{q}$ are the d- and q-axes components of armature currents, $u_{d}^{*}$ and $u_{q}^{*}$ are the d- and q-axes of terminal voltages, $\Psi_{f}$ are the permanent magnet flux linkage, $L_{d}$ and ${\hat{L}}_{q}$ are the d- and q-axes stator inductances, $u_{d e c}, u_{q e c}$ are the decoupling voltages.

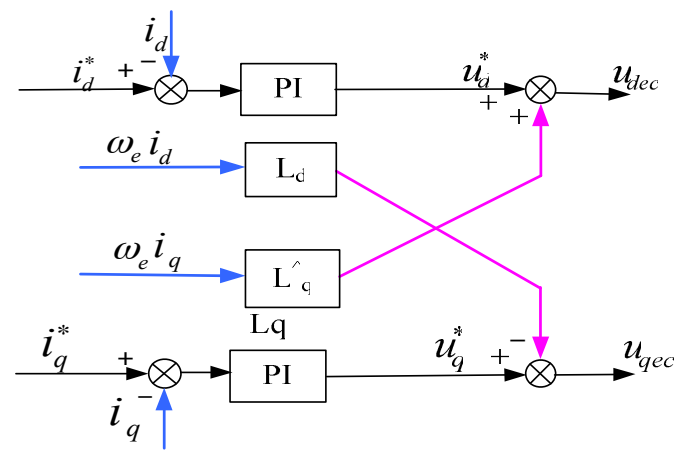

Figure 5: Decoupling model with parameters compensation

\section{Control System and Results}

Figure.6 describes the variable-speed IPMSM drive system on which the decoupling scheme is investigated. In the constant torque region, the reluctance torque developed by saliency is exploited through the maximum torque per ampere control strategy. In the constant power region, the flux-weakening control is used to extend the speed range. The parameters of IPM motor are listed in the Table.1. 


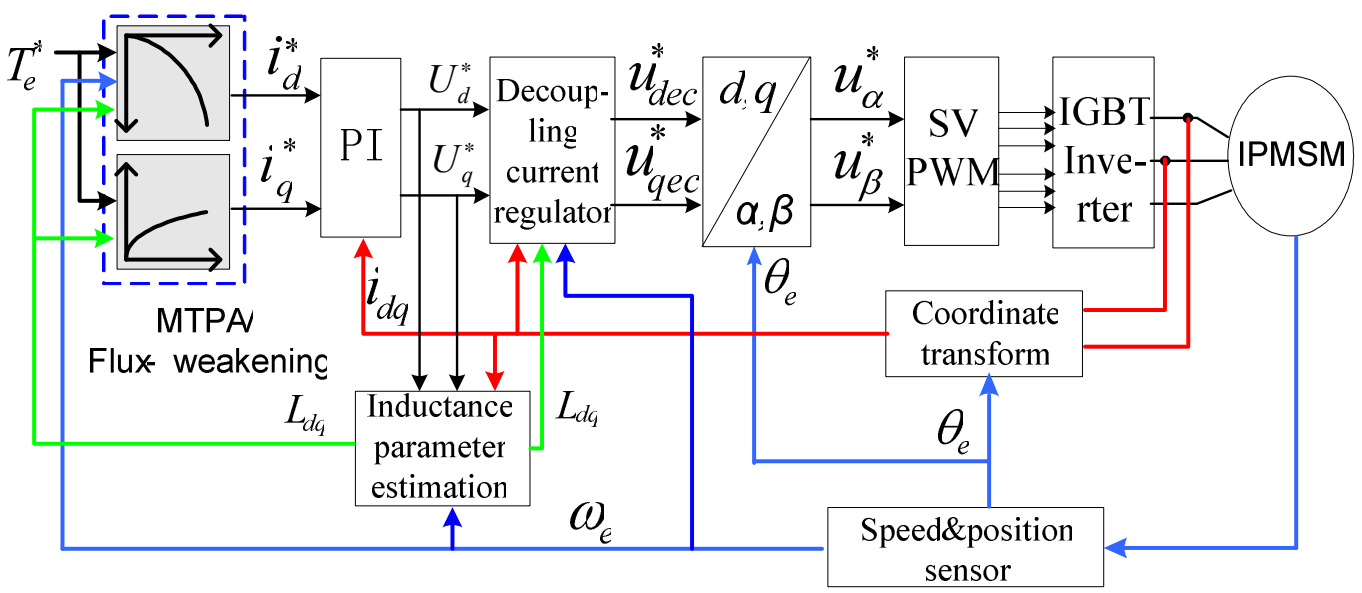

Figure 6: Control block diagram of the proposed strategy for IPMSM with compensation of magnetic saturation

Table 1: A 7.5kW IPM motor parameters

\begin{tabular}{|c|c|}
\hline Parameter & Value \\
\hline Number of pole pairs & 4 \\
\hline Armature resistance & $0.025 \Omega$ \\
\hline Magnet flux-linkage & $0.062 \mathrm{~Wb}$ \\
\hline D-axis inductance & $0.2 \mathrm{mH}$ \\
\hline Q-axis inductance & $0.47 \mathrm{mH}$ \\
\hline Maximum torque & $24 \mathrm{~N} \cdot \mathrm{m}$ \\
\hline Output power & $7.5 \mathrm{~kW}$ \\
\hline Maximum speed & 6500rpm \\
\hline
\end{tabular}

compensation of terminal voltage and this effect is apparent, especially in high-speed range, as shown in figure.7.The motor start quickly to the commanded speed by higher start torque, and the followed performance is ideal, no overshoot. When added the $5 N \cdot m$ load at $0.15 \mathrm{~s}$, the speed reduce slightly and is recovered immediately. Then the control system step up from 1000rmp to 3000rpm at $0.25 \mathrm{~s}$ and it with decoupling control reaches the commanded speed faster than ones without decoupling control. The decoupling control makes motor mathematical models linear and control system stabilizing fast when added load torque. The start torque is improved and the motor reaches quickly the commanded speed, i.e the dynamic performance is optimal. The inductance parameter estimation model established in control system compensates the effect of magnetic saturation, as shown in figure.8. The IPMSM control system with compensation of magnetic saturation extends speed range and improves the output torque in high speed range.

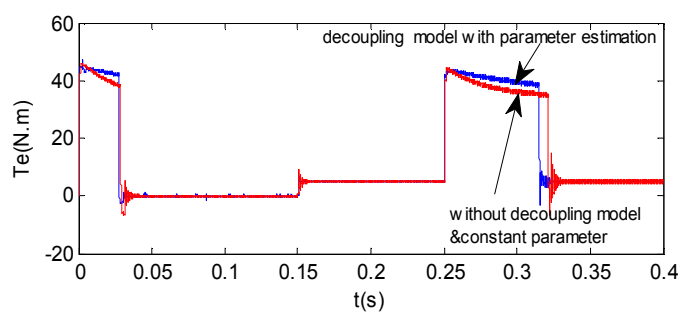

(a)

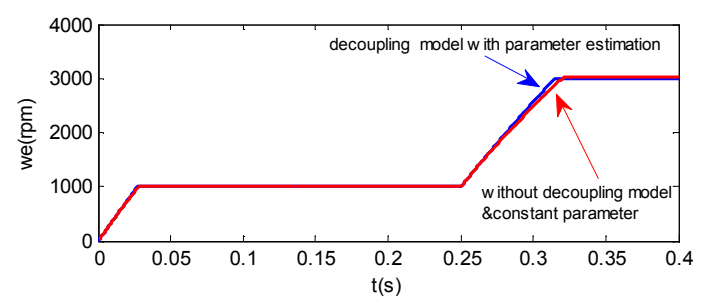

(b)

Figure 7: Step responses of speed and torque with and without decoupling compensation in flux-weakening range

$\left(w^{*}: 1000 \rightarrow 3000 \mathrm{rpm}, \mathrm{Te}: 0 \rightarrow 5 \mathrm{~N} \cdot \mathrm{m}\right)$ (a) Torque, (b) Speed, 


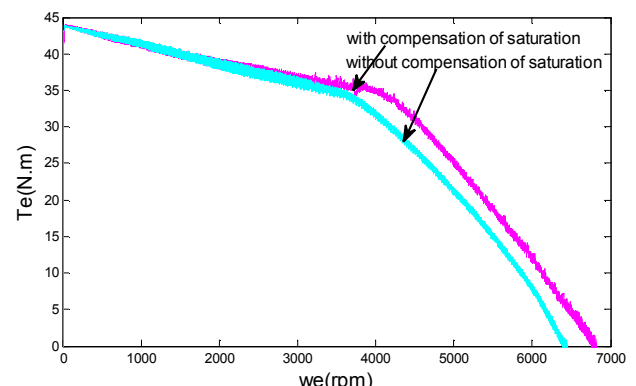

Figure 8: Torque versus speed with and without compensation of saturation

\section{Conclusion}

The simulation results indicate that the decoupling control method can effectively improve the system following-up performance, robustness and control accuracy. The decoupling control with parameter estimation eliminates cross-coupling effects and unstable transient responses due to saturation of current controller caused by the terminal voltage exceeding the limited voltage in high-speed flux-weakening range. The compensation of magnetic saturation extends the speed range and improves output torque in flux-weakening region. The on-line parameter estimation model of closed loop observer is reliable to follow the real parameter in machine. Therefore, it should find a wide application in the design of high-performance drive system for interior permanent magnet motor taking account for magnetic saturation.

\section{References}

[1] B. Sneyers, D.W. Novotny, T.A Lipo, Field-Weakening in Buried Permanent Magnet AC Motors Drives, IEEE Trans. on Ind. Appl., vol. IA-21, pp. 398-407, Mar./Apr. 1985.

[2] T.M. Jahns, G.B. Kliman, T.W. Neumann, Interior Permanent- Magnet Synchronous Motors for Adjustable-Speed Drives, IEEE Trans. on Ind. Appl., vol. IA-22, pp. 738-747, July/Aug. 1986.

[3] J-W Park, K-H Koo, J-M Kim, Improvement of
Control Characteristics of Interior Permanent Magnet Synchronous Motor for Electric Vehicle, Rec. of Ind. Appl. Soc. Ann. Mtg, Rome, pp. 1888-1895. 2000.

[4] Shigeo Morimoto, Masayuki Sanada,and Yoji Takeda, Effects and Compensation of Magnetic Saturation in Flux-Weakening Controlled Permanent Magnet Synchronous Motor Drives, IEEE TRANSACTIONS ON INDUSTRY APPLICATIONS, VOL. 30, NO. 6, pp1632-1637. NOVEMBER / DECEMBER 1994.

[5] G. H. Kang, J. P. Hong, G. T. Kim, and J. W. Park, Improved parameter modeling of interior permanent magnet synchronous motor based on finite element analysis, IEEETrans. Ma@., vol. 36, no. 4, pp. 1867-1870, July. 2000.

[6] Edward C. Lovelace, Thomas M. Jahns, Fellow, IEEE, and Jeffrey H. Lang Impact of Saturation and Inverter Cost on Interior PM Synchronous Machine Drive Optimization, IEEE TRANSACTIONS ON INDUSTRY APPLICATIONS, VOL. 36, NO. 3, pp723- 729 MAY/JUNE 2000.

[7] Emil Levi, Member, IEEE, and Viktor A. Levi Impact of Dynamic Cross-Saturation on Accuracy of Saturated Synchronous Machine Models IEEE TRANSACTIONS ON ENERGY CONVERSION, VOL. 15, NO. 2, JUNE 2000 pp224- 230

[8] Bojan `Stumberger, Gorazd `Stumberger, Drago Dolinar, Anton Hamler, and Mladen Trlep, Evaluation of Saturation and Cross-Magnetization Effects in Interior Permanent-Magnet Synchronous Motor, IEEE TRANSACTIONS ON INDUSTRY APPLICATIONS, VOL. 39, NO. 5, SEPTEMBER/OCTOBER 2003 , pp.1264 - 1271

[9] Hyunbae Kim and R.D. Lorenz, Improved Current Regulators for IPM Machine Drives Using On-Line Parameter Estimation IEEE Trans. Ind. Appl., vol. 1, pp.86-91, 13-18Oct. 2000

[10] Zhao Ke, An Quntao, Sun Li, Modeling and Simulation of Adaptive Identification for PMSM 
Parameters, Journal of System Simulation, vol.21

No.12, pp3552-3556. Jun .2009

\section{Author}

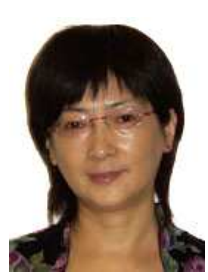

Aimeng Wang, Ph.D. degree, associate profess of North China Electric Power University. She has been engaged in design and drive system of permanent magnet machine.

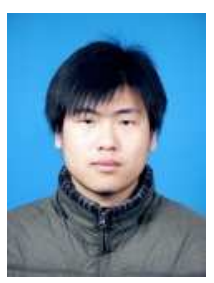

Xingwang, Master degree, Study in North China Electric Power University. Her research interest in permanent magnet machine drive control system.

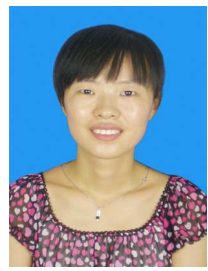
Wenjuan Shi, Master degree, Study in North China Electric Power University. Her research interest in permanent magnet machine drive control system. 